\title{
PERFORMANCE ENHANCEMENT OF LEACH, V-LEACH AND MOD-LEACH CLUSTERING ROUTING PROTOCOLS FOR WIRELESS SENSOR NETWORKS
}

\begin{tabular}{|l|l|}
\hline Devika G & Asha Gowda Karegowda \\
Associate Professor, & Assistant Professor, \\
Department of CSE, & Department of MCA, \\
Government Engineering College, & Siddaganga Institute of Technology, \\
K R Pet, Mandya Dist. & Tumkur \\
\hline
\end{tabular}

\begin{abstract}
A wireless sensor network (WSN) is a wireless network consisting of spatially distributed autonomous devices using sensors to monitor physical or environmental conditions. Sensor nodes have a limited transmission range, and their processing and storage capabilities as well as their energy resources are also limited. Routing protocols for wireless sensor networks have to ensure reliable communication under these conditions. In such situation cluster based routing is a suitable solution to enhance the energy efficiency for nodes in wireless sensor networks when compared to flat routing. In this paper, authors have attempted to improve the performance of three energy efficient hierarchical clustering protocols namely: LEACH, VLEACH and MODLEACH by using both residual energy and distance. Performance of proposed method is compared in terms of different matrices such as network lifetime, throughput and time of first dead node for non uniform distribution of sensor nodes. Simulations results are validated by using MATLAB. The proposed protocols Var-LEACH, Var-VLEACH and Var-MODLEACH have improved the lifetime of WSN when compared to LEACH, VLEACH and MODLEACH.
\end{abstract}

Keywords - Wireless sensor networks, LEACH, VLEACH, MODLEACH, Var-LEACH, Var-VLEACH, Var-MODLEACH.

\section{INTRODUCTION}

Wireless sensor networks have potential to monitor environments for both military and civil applications. The ability to add remote sensing points, without the cost of running wires, results in numerous benefits including energy and material savings, process improvements, labor savings, and productivity increases [1]. Nodes in wireless sensor network are capable of performing some processing, gathering sensory information and communicating with other connected nodes in the network. In sensor nodes, radio communication is the main energy dissipation factor [2] [3]. Due to this factor nodes are constrained by energy consumption after being deployed in their operational area, for this reason designing a WSN routing protocol must concern on enhancing energy efficiency and extending the lifetime of the WSN. In general, routing in WSNs can be divided into flat-based routing, hierarchical-based routing and locationbased routing depending on network structure. Hierarchical routing is the procedure of arranging routers in a hierarchical manner. Existing cluster based hierarchical routing protocols either assumes direct communication between cluster heads and base station or through multi-hops in some scenarios. Hierarchical routing algorithms are based on clustering is a best solution for enhancing network life time. It uses localized co ordination to enable scalability and robustness for dynamic networks and incorporate data fusion into the routing protocols to reduce the amount of information that must be transmitted to the base station. In cluster based protocol, nodes are partitioned into a number of small groups, called clusters, for aggregating data through efficient network organization [4]. Clustering improves the scalability of wireless sensor networks. This is because clustering minimizes the need for central organization and promotes local decisions [5]. A cluster based protocol LEACH is renowned for its success in extending the lifetime of wireless sensor networks. 
ELK

Asia Pacific Journals

\section{WORKING OF LEACH, VLEACH AND MODLEACH}

LEACH [6] protocol is the first hierarchical cluster based routing protocol successfully used in the wireless sensor network. LEACH is a clustering -based protocol that utilizes randomized rotation of local cluster Heads $[\mathrm{CH}]$ to evenly distribute the energy load among sensors in the network. It uses localized coordination to enable scalability and robustness for dynamic networks and incorporate data fusion into the routing protocols to reduce the amount of information that must be transmitted to the base station. This protocol alters the cluster head at every round and once a cluster head is formed, it will next chance after the next $1 / p$ rounds. For every round, cluster heads are replaced and whole cluster formation process is undertaken. In case of LEACH if a cluster head node dies due to some calamities, then nodes in a cluster will be without a cluster head until the next cluster formation round begins. To overcome such situations VLEACH [7] was introduced, where in addition to cluster head, it identifies vice cluster head, which will become cluster head if cluster head node dies.

MODLEACH [8] was introduced which used efficient cluster head replacement scheme. If existing cluster has more energy than required threshold, it will remain cluster head for the next round as well. This is how, energy wasted in routing packets for new cluster head and cluster formation can be saved. If cluster head has less energy than required threshold, it will be replaced according to LEACH algorithm.

LEACH Algorithm: The operation is broken up into rounds, each round incorporates 2 phases: set-up phase and steady phase. To minimize the overhead steady phase is longer than set-up phase.

\section{A. Setup phase}

- Node decides whether to become a cluster head $(\mathrm{CH})$ or not for current round based
ELK Asia Pacific Journals - Special Issue ISBN: 978-81-930411-5-4

on the suggested percentage of $\mathrm{CH}$ for the network.

- Nodes choose the number between 0 and 1.

- If selected number is less than $T(n)$ as in equation 1, the node becomes $\mathrm{CH}$.

$$
T(n)=\frac{p}{1-p *(\bmod 1 / p)} \text { if } n \in G
$$

(1)

where, the desired percentage of cluster heads, the current round, and $\mathrm{G}$ is the set of nodes hat have not been cluster-heads in the last $1 / p$ rounds.

- The node selected as a $\mathrm{CH}$ broadcast advertisement message to rest of the nodes

- Non $\mathrm{CH}$ decides to join the cluster based on the signal strength received from the $\mathrm{CH}$.

- Nodes inform the $\mathrm{CH}$ by transmitting the join request to the $\mathrm{CH}$.

- $\mathrm{CH}$ receives all the messages from the nodes and schedules a TDMA for each of the nodes in its cluster.

\section{B. Steady state phase involves}

- The sensed information will be transmitted to the $\mathrm{CH}$ in its scheduled time.

- $\mathrm{CH}$ collects frames from all the nodes in the cluster and aggregates the data and transmits the data to the $\mathrm{BS}$ using CDMA code.

MODLEACH routing algorithm incorporates an efficient cluster head replacement scheme and dual transmitting power levels. The operation is divided into rounds consisting of setup and steady phase. The functioning of the algorithm remains same as in LEACH. In setup phase, in first round the selection of the cluster head is done using randomized method of LEACH. But, in next 
consecutive rounds before embarking on to next round current $\mathrm{CH}$ residual energy is compared with the threshold. If energy level is more, then even for this level it will continue as a $\mathrm{CH}$. In case of steady phase, non $\mathrm{CH}$ nodes do not send sensed data regularly. But, nodes will compare sensed data with hard threshold and soft threshold values send by the $\mathrm{CH}$. For first time if sensed value greater than hard threshold value it transmit to the $\mathrm{CH}$. For the next iterations if sensed value is more than the hard threshold it once again compares with sent soft threshold value, if sensed value is less then soft threshold value then nodes will transmit data.

The LEACH, mod LEACH and VLEACH are suitable for WSNs, where all sensor nodes are identical and charged with the same amount of initial energy. All nodes consume energy at the same rate. They are able to know their residual energy and distance. Every node has the capability to support different MAC protocol and data processing. All communication channels are identical. The MODLEACH are suitable for data centric and remote deploying applications. The VLEACH is suitable for large sized network as well as sparse nodes network applications.

\section{PROPOSED WORK}

Although LEACH, MOD-LEACH and VLEACH routing protocol has many advantages for WSN in clustering organization, they do not consider residual energy of candidate nodes as well as distance from the BS. Therefore there is a chance of node with low residual energy as well as node farther from BS becoming $\mathrm{CH}$. In the proposed protocol few reasonable assumptions are made, all nodes deployed within a square area are homogeneous; nodes and BS are stationary after deployment; nodes use only the initial battery power and are not recharged, and nodes are location-aware. The selection of $\mathrm{CH}$ in original LEACH protocol, MODLEACH and VLEACH are based on only probability values. So, those nodes which are farther from the BS and with low residual energy may have the probability of selecting as $\mathrm{CH}$. Authors have proposed the following method for selection of $\mathrm{CH}$ nodes ( among the nodes which are not $\mathrm{CH}$ in the most recent $1 / \mathrm{p}$ rounds) whose probability is computed using equation 2.

$p_{i}=\frac{E_{\text {residwal(i) }}}{E_{\text {average }}} X \frac{\text { max_dist_to_BS }}{\operatorname{Dis}(i, B S)}$

where, $E_{\text {residual }(i)}$ is the residual energy of candidate node $i$ at the current time, $E_{\text {average }}$ denotes the average energy of all live nodes in WSN. Dis $(i, B S)$ is the geographic distance from the candidate node to the BS and max_dist_to_BS is the value factor that is computed after deploying the network.

After $\mathrm{CH}$ selection, the $\mathrm{CHs}$ broadcast its message of selection as $\mathrm{CH}$ to other nodes. The non- $\mathrm{CH}$ nodes join $\mathrm{CH}$ by decision based on join criterion which is estimated as in equation 3 and not by signal strength as in LEACH, VLEACH and MODLEACH protocols.

$j_{\text {join }}$ criterion $(i, C H j)=\operatorname{Max}\left[\frac{E_{\text {residual }}(C H j)}{\operatorname{dis}\left(B S_{,} C H j\right)+\operatorname{dis}\left(i_{i}, C H j\right)}\right]$ (3)

where, $d(B S, C H j)$ is the node $j$ 's distance from $\mathrm{BS}, \operatorname{dis}(i, \mathrm{CH})$ are the distance from node $i$ to $C H j$. Distance between two nodes $d(a, b)$ is computed as in equation 4 .

$|d(a, b)|=\sqrt{\left(x_{a}-x_{b}\right)^{2}+\left(y_{a}-y_{b}\right)^{2}}$

(4)

\section{EXPERIMENTAL RESULTS AND DISCUSSIONS}

Simulations are conducted using MAT LAB. Table 1 shows the network parameters. In a wireless sensor network computing capacity and stored energy is limited. Due to these limiting computing capacities, network lifetime and throughput is affected. Thus in the simulations evaluated using following parameters. 
a) Network Life span: The network lifespan of the sensor network is the lifetime of the network from the beginning of the network to the instant that, it no longer provides readable information of the network. It means the time from where the network starts its operation till the phase network has completed its operation. The operation is measured in terms of the rounds. Thus the network lifetime is measured in three ways the round in which first node dies, number of alive nodes and dead nodes for different rounds. Figure1 (a-c) and Figure 2 (a-c) depicts the comparison of number of alive nodes against the rounds and number of dead nodes against the rounds for LEACH vs. proposed Var-LEACH, MODLEACH vs. proposed Var-MODLEACH and VLEACH vs. proposed Var-VLEACH respectively. The round number of first node dead and last node dead is shown in Table 2. The information of both alive and dead nodes in different rounds for the six protocols is summarized in Table 3.

b) Throughput: $A$ base station receiving more data packets confirms the efficiency of routing protocol. The throughput of the sensor network is measured by the total number of packets sent to base station by the cluster heads and by packets sent by non cluster head to cluster heads during the network lifetime and cluster head formation. Figure 3 (a-c) depicts the number of packets sent from cluster head to the $\mathrm{BS}$ in each round for LEACH vs. proposed LEACH, MODLEACH vs. proposed Var-MODLEACH and VLEACH vs. proposed Var-VLEACH respectively. Throughput in terms of number of packets sent to BS is summarized in Table 4.

Among all the protocols discussed Var-VLEACH performs better under sensor networks it uses the distributed localized clustering formation as well as VCH. But if we take the data-centric applications Var-MODLEACH performs better in terms of longevity of networks.

\section{v. CONCLUSIONS}

In this work, a brief description of three commonly used hierarchical clustering based WSN routing protocols namely LEACH, VLEACH and MODLEACH. These protocols do not consider residual energy of candidate nodes as well as distance from the BS. Therefore there is a chance of node with low residual energy as well as node farther from BS becoming $\mathrm{CH}$. The proposed protocols namely Var-LEACH, VarVLEACH and Var-MODLEACH selects the $\mathrm{CH}$ considering both residual energy of candidate nodes as well as distance from the BS. In addition to this the non- $\mathrm{CH}$ nodes join $\mathrm{CH}$ by decision based on join criterion. The protocols tend to minimize network energy consumption by efficient cluster head selection after very first round. The future works aims at selection of the cluster by considering multihops. In addition it is planned to design protocols which spend least time for data fusion at $\mathrm{CH}$ and much more efficient mechanisms for the cluster head replacement. Simulation results clearly depict that proposed Var-LEACH, Var-VLEACH and Var-MODLEACH has improved the lifetime of LEACH, VLEACH and MODLEACH.

\section{REFERENCES}

[1] N. Narasimha datta and K.Gopinath , ”A survey of routing algorithms for wireless sensor networks", J. Indian Inst. Sci., Nov.-Dec. 2006, 86, 569-598.

[2] A.Sinha, A Chandrakasan, "Dynamic power management in wireless sensor networks", IEEE Design \& Test of computers, Vol.18,Issue 2, 2001, pp. 6274.

[3] V Raghaunathan, C Schurgers, S Park and Mani B Srivastava, "Eneergy-aware wireless microsensor networks", IEEE signal processing magazine, Vol. 19, Issue 2, March 2002, pp. 40-50.

[4] O. Younis, M. Krunz, and S. Ramasubramanian. Node clustering in 
ELK

Asia Pacific Journals wireless sensor networks: Recent developments and deployment challenges. IEEE Network, 20(3):20-25, 2006.

[5] Neeraj Kumar Mishra, Vikram Jain, Sandeep Sahu, "Survey on Recent Clustering Algorithms in Wireless Sensor networks" , International Journal of Scientific and Research Publications, Volume 3, Issue 4, April 20131 ISSN 2250-3153 www.ijsrp.org.

[6] W.B. Heinzelman, A. Chandrakasan, H. Balakrishnan, An application-specific protocol architecture for wireless microsensor networks, IEEE Trans. Wireless Commun. 1 (4) (2002) 660-670.
[7] M. Bani Yassein, A. Al-zou'bi, Y. Khamayseh, W. Mardini, “ Improvement on LEACH Protocol of Wireless Sensor Network(VLEACH) "International Journal of Digital Content Technology and its Applications Volume 3, Number 2, June 2009.

[8] D. Mahmood, N. Javaid, S. Mehmood, S. Qureshi, A.M. Memon, T. Zaman, "MODLEACH: a variant of LEACH for WSNs 26th IEEE Canadian Conference on Electrical and Computer Engineering (CCECE2013), Regina, Saskatchewan, Canada, 2013.

Table 1. Network parameters nodes

\begin{tabular}{|l|l|l|}
\hline Sl no. & \multicolumn{1}{|c|}{ Network parameters } & \multicolumn{1}{c|}{ value } \\
\hline 1 & Network size & $400 \mathrm{X} 400 \mathrm{~m}^{2}$ \\
\hline 2 & Number of nodes & 100 \\
\hline 3 & Sensor nodes initial energy & $0.5 \mathrm{~J}$ \\
\hline 4 & Packet size & $4000 \mathrm{bits}$ \\
\hline 5 & Energy consumption in idle state & $50 \mathrm{~nJ} / \mathrm{bit}$ \\
\hline 6 & Data aggregation & $5 \mathrm{~nJ} / \mathrm{bit} / \mathrm{report}$ \\
\hline 6 & Energy dissipation of the transmission amplifier & $100^{*} 10^{\wedge}(-12)$ \\
\hline 7 & Amplification energy(cluster to BS), $\mathrm{E}_{\mathrm{mp}}$ & $0.00013 \mathrm{pJ} / \mathrm{bit} / \mathrm{m}^{2}$ \\
\hline 8 & Amplification energy(cluster to BS) $\mathrm{E}_{\mathrm{fs}}$ & $10 \mathrm{PJ} / \mathrm{bit} / \mathrm{m}^{2}$ \\
\hline 9 & Fusion rate & 0.6 \\
\hline 10 & Control Message size & $32 \mathrm{bits}$ \\
\hline
\end{tabular}

Table 2. Life time of network nodes

\begin{tabular}{|c|c|c|}
\hline Protocol & $\begin{array}{c}\text { Round number of First } \\
\text { dead node }\end{array}$ & $\begin{array}{c}\text { Round number of Last } \\
\text { dead node }\end{array}$ \\
\hline LEACH & 8 & 1880 \\
\hline MOD LEACH & 309 & 2336 \\
\hline VLEACH & 9 & 2360 \\
\hline VLEACH & 256 & 2003 \\
\hline
\end{tabular}




\begin{tabular}{|c|c|c|}
\hline $\begin{array}{c}\text { Var- } \\
\text { MODLEACH }\end{array}$ & 319 & 2473 \\
\hline Var-VLEACH & 23 & 2578 \\
\hline
\end{tabular}

Table 3. Variation of number of alive and dead nodes nodes and number

\begin{tabular}{|c|c|c|c|c|c|c|c|c|c|c|c|c|}
\hline \multirow{2}{*}{$\begin{array}{l}\text { Round } \\
\text { number }\end{array}$} & \multicolumn{6}{|c|}{ Number of Alive nodes } & \multicolumn{6}{|c|}{ Number of dead nodes } \\
\hline & $\begin{array}{l}\text { L } \\
\text { E } \\
\text { A } \\
\text { C } \\
\text { H }\end{array}$ & $\begin{array}{c}\text { MO } \\
\text { DLE } \\
\text { ACH }\end{array}$ & $\begin{array}{l}\text { VL } \\
\text { EA } \\
\text { CH }\end{array}$ & $\begin{array}{c}\text { Var- } \\
\text { LEA } \\
\text { CH }\end{array}$ & $\begin{array}{c}\text { Va } \\
\text { r- } \\
\text { M } \\
\text { O } \\
\text { DL } \\
\text { EA } \\
\text { C } \\
\text { H }\end{array}$ & $\begin{array}{l}\text { Var- } \\
\text { VLE } \\
\text { ACH }\end{array}$ & $\begin{array}{c}\text { LE } \\
\text { AC } \\
\mathbf{H}\end{array}$ & $\begin{array}{c}\text { MO } \\
\text { DLE } \\
\text { AC } \\
\text { H }\end{array}$ & $\begin{array}{l}\text { VL } \\
\text { EA } \\
\text { CH }\end{array}$ & $\begin{array}{c}\text { Var } \\
- \\
\text { LE } \\
\text { AC } \\
\text { H }\end{array}$ & $\begin{array}{c}\text { Var- } \\
\text { MOD } \\
\text { LEAC } \\
\text { H }\end{array}$ & $\begin{array}{c}\text { Va } \\
\text { r- } \\
\text { VL } \\
\text { EA } \\
\text { CH }\end{array}$ \\
\hline 10 & 90 & 100 & 96 & 100 & $\begin{array}{l}10 \\
0\end{array}$ & 100 & 10 & 0 & 4 & 0 & 0 & 0 \\
\hline 500 & 54 & 80 & 85 & 78 & 90 & 96 & 48 & 20 & 15 & 22 & 10 & 4 \\
\hline 1000 & 27 & 32 & 67 & 44 & 40 & 65 & 63 & 68 & 33 & 56 & 60 & 35 \\
\hline 1500 & 10 & 6 & 33 & 15 & 22 & 32 & 90 & 94 & 67 & 85 & 78 & 68 \\
\hline 2000 & 4 & 0 & 18 & 6 & 11 & 19 & 96 & 100 & 92 & 94 & 89 & 81 \\
\hline 2500 & 0 & 0 & 0 & 0 & 0 & 0 & 100 & 100 & 100 & 100 & 100 & 100 \\
\hline
\end{tabular}



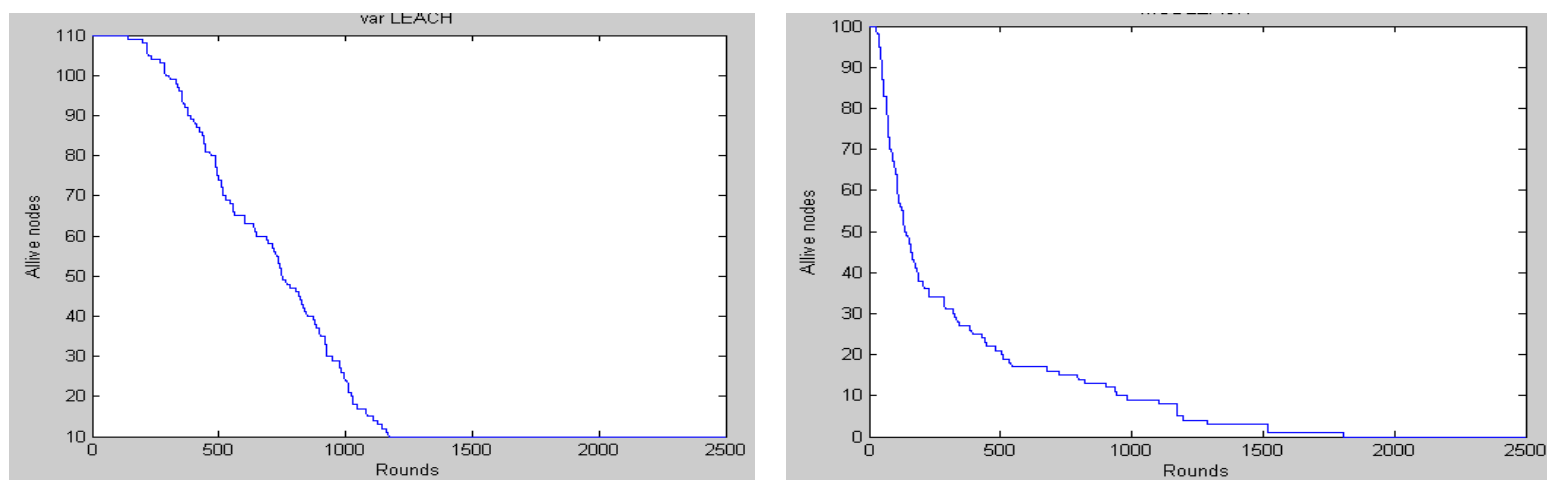

Fig 1 (a) Comparison of number of alive nodes : Var- LEACH vs LEACH
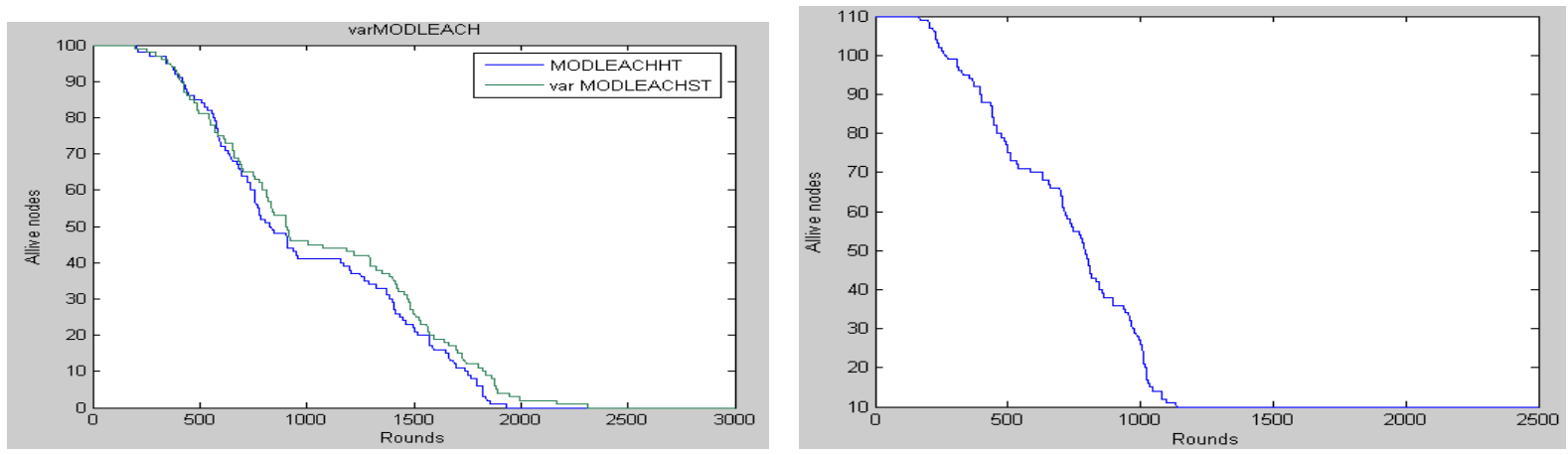

Fig 1(b) Comparison of number of alive nodes: Var-Proposed
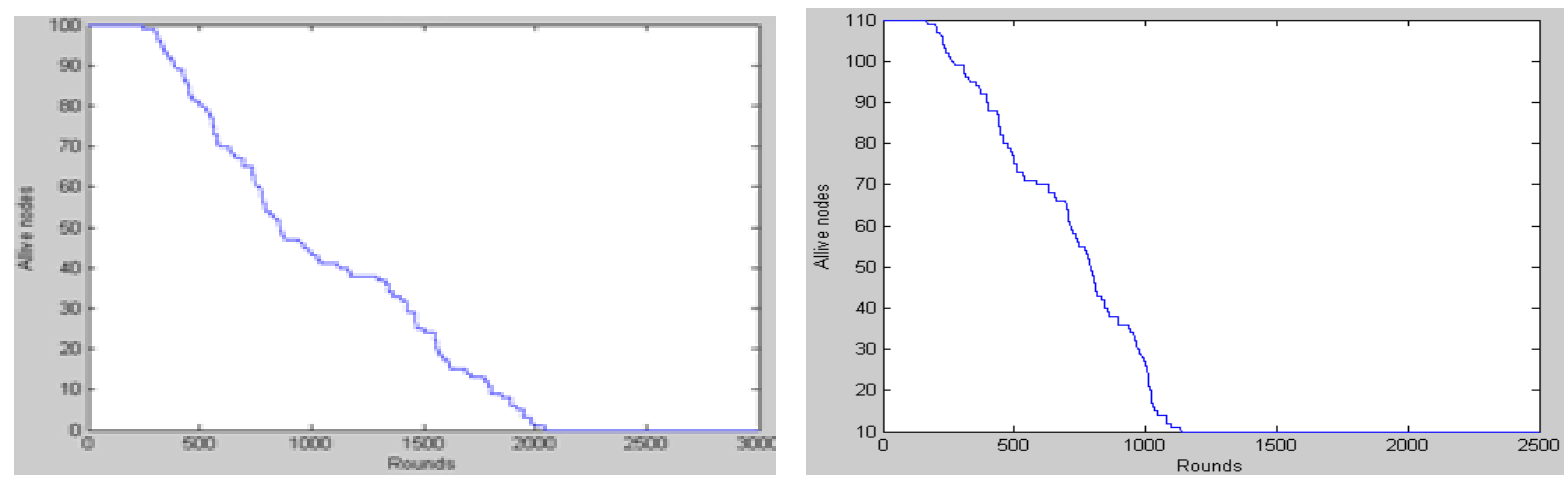

Fig 1(c) Comparison of number of alive node: Var-VLEACH vs. 

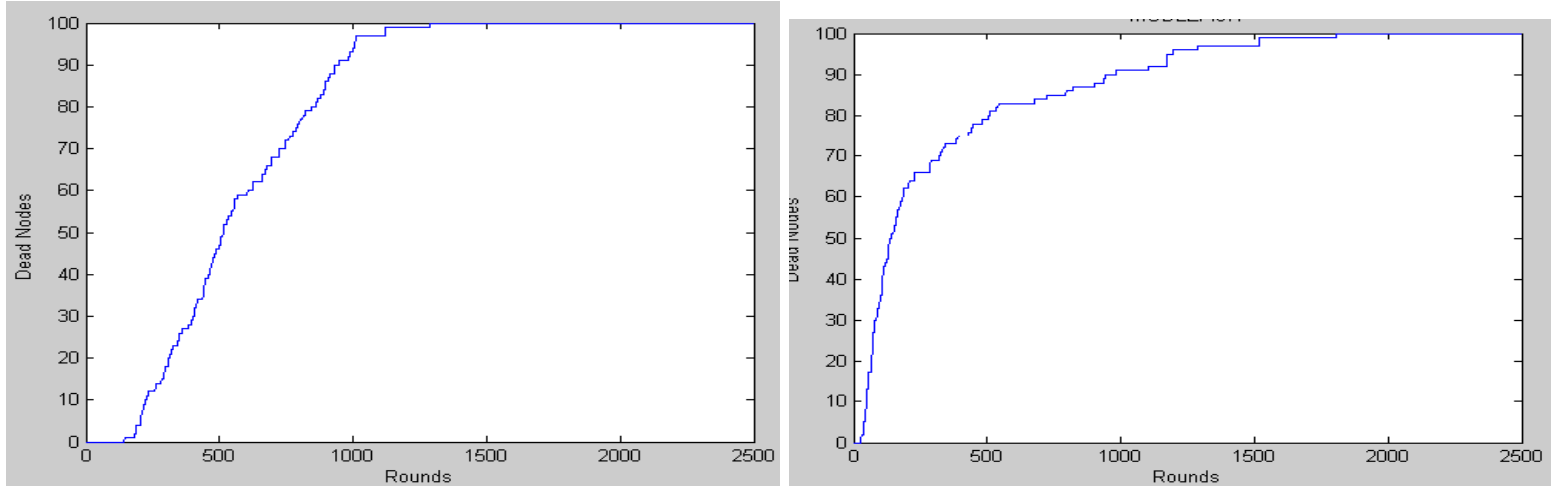

Fig 2 (a) Comparison of number of dead nodes: Var- LEACH vs. LEACH
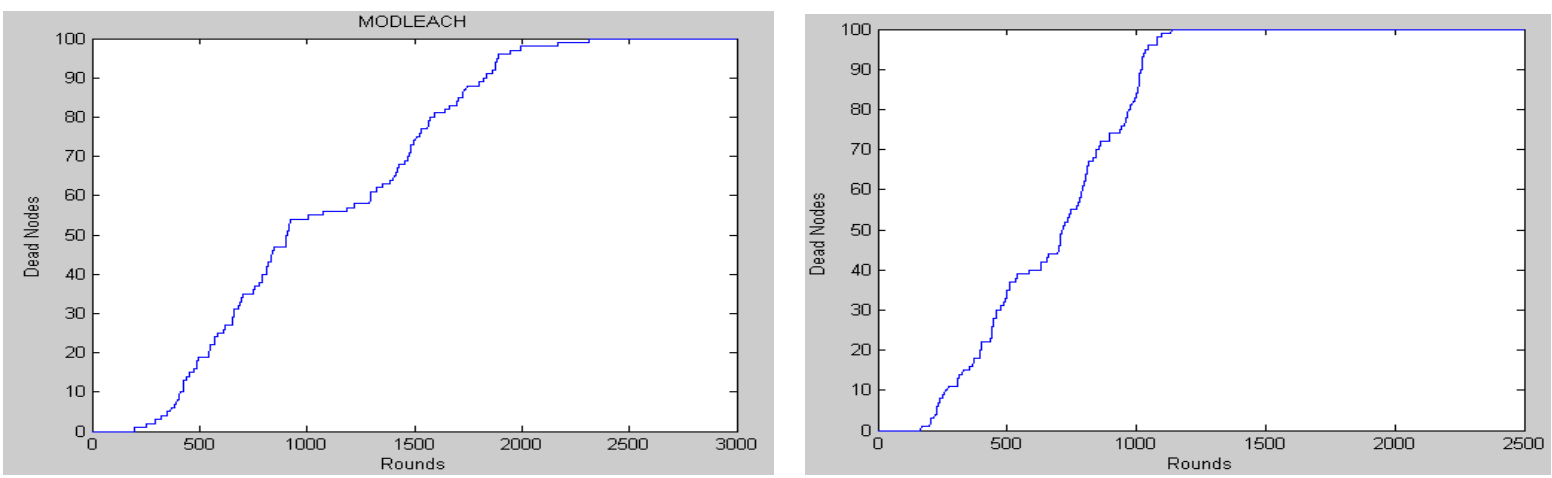

Fig 2(b) Comparison of number of dead nodes: Var- MODLEACH vs.MODLEACH
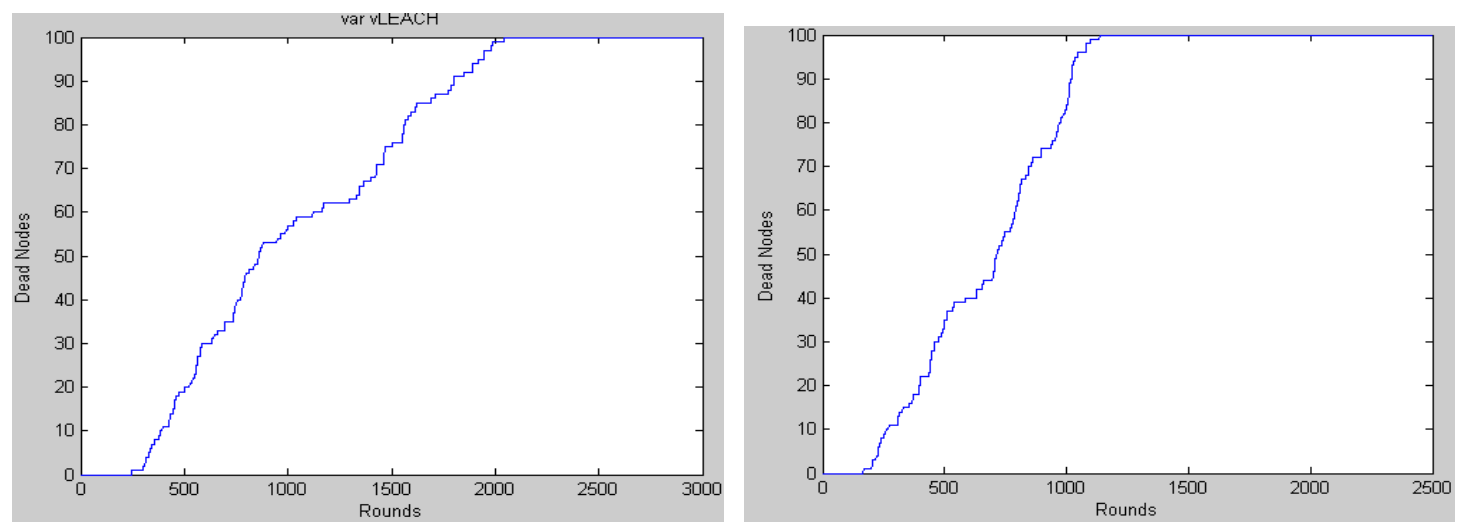

Fig 2(c) Comparison of number of dead nodes: Var-VLEACH vs.Var-VLEACH 
Asia Pacific Journals
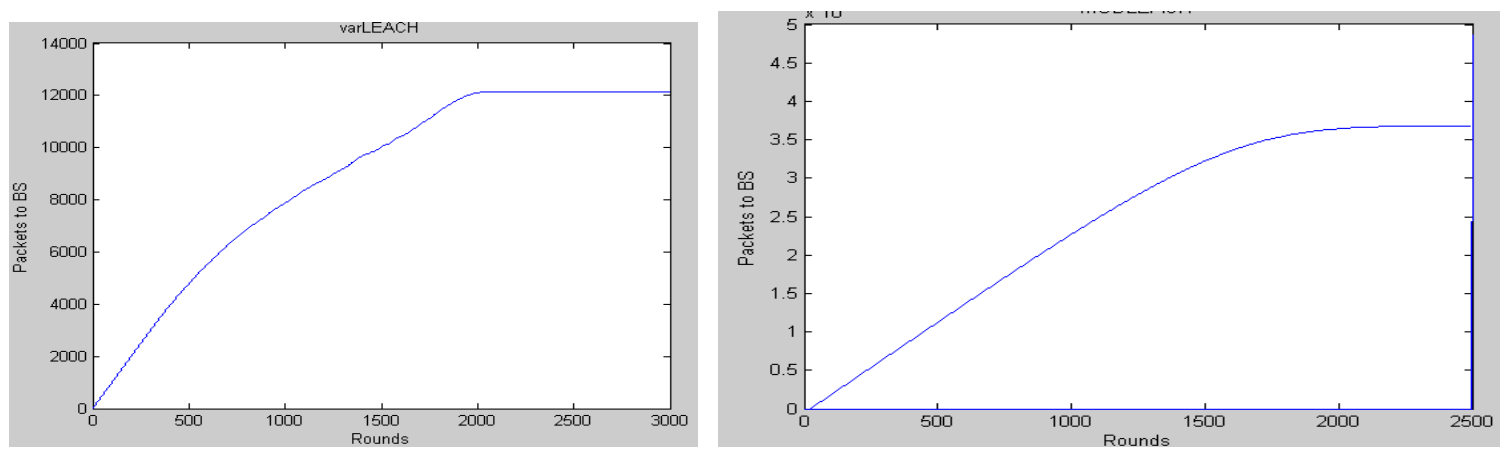

Fig 3(a) Comparison of number of packets sent to BS Var-LEACH \& LEACH
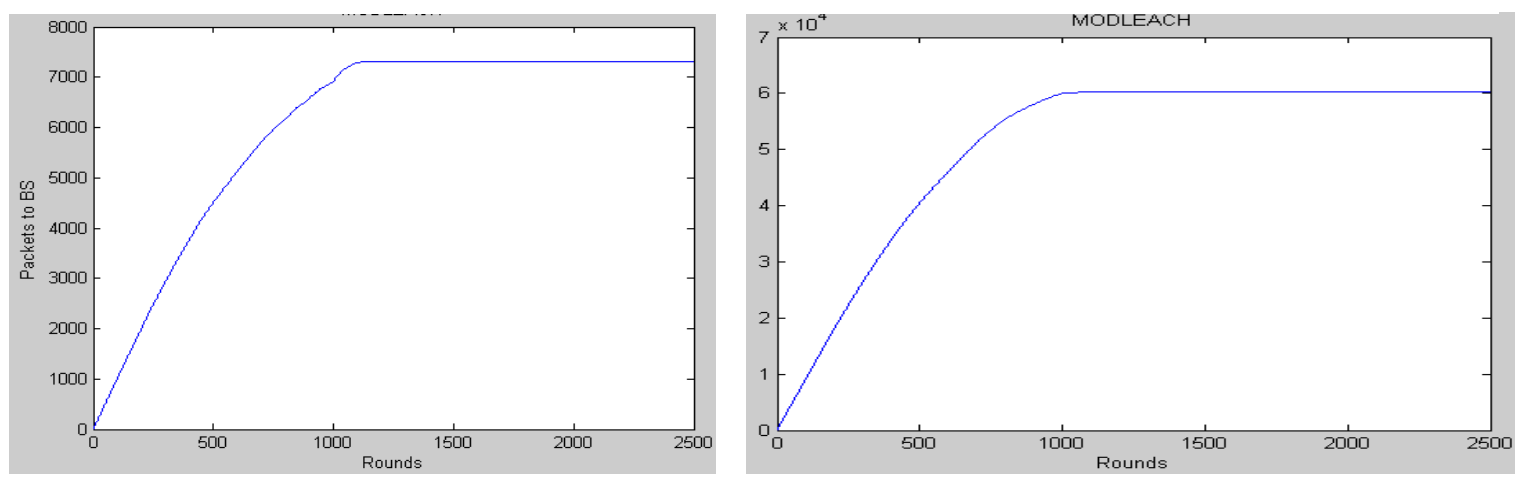

Fig 3(b) Comparison of number of packets sent to BS Var-MODLEACH \& MODLEACH
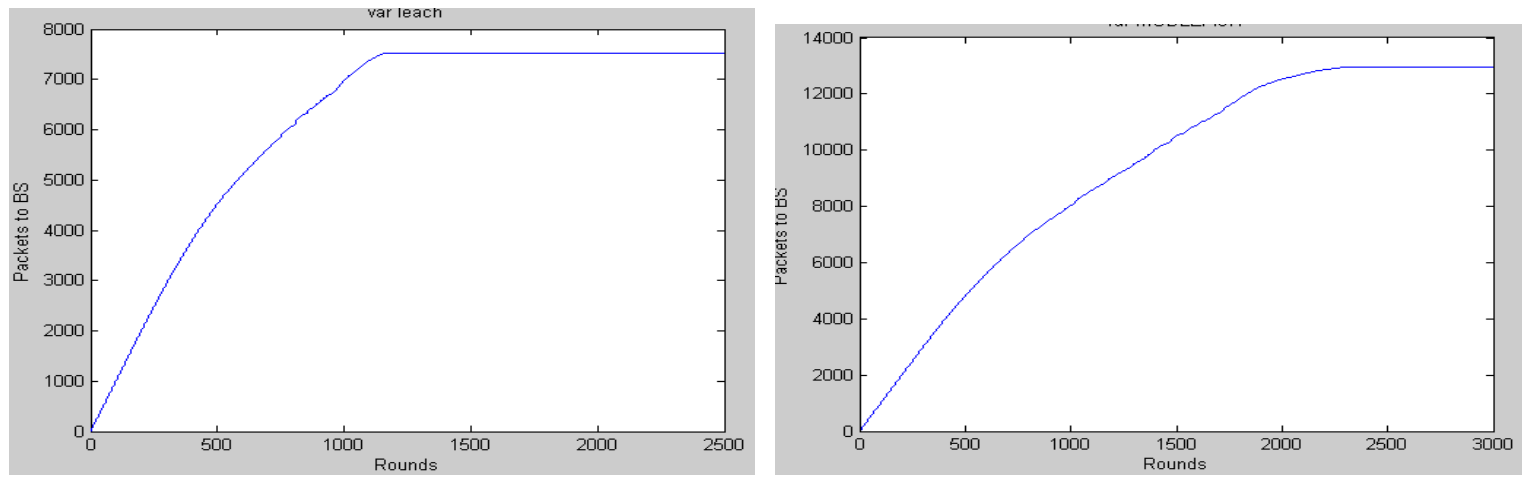

Fig 3(c) Comparison of number of packets sent to BS Var-VLEACH \& VLEACH 
Table 4: Throughput In Terms Of Number Of Packets Sent To Bs

\begin{tabular}{|l|l|l|l|l|l|l|}
\hline & \multicolumn{7}{|c|}{ Number of packets sent to BS } \\
\hline $\begin{array}{l}\text { Round } \\
\text { number }\end{array}$ & LEACH & MODLEACH & VLEACH & $\begin{array}{l}\text { Var- } \\
\text { LEACH }\end{array}$ & $\begin{array}{l}\text { Var- } \\
\text { MODLEACH }\end{array}$ & $\begin{array}{l}\text { Var- } \\
\text { VLEACH }\end{array}$ \\
\hline 10 & 6192 & 2021 & 6336 & 10492 & 2050 & 98624 \\
\hline 500 & 6336 & 9597 & 5832 & 11956 & 9846 & 93264 \\
\hline 1000 & 4680 & 16005 & 4601 & 11834 & 16665 & 100768 \\
\hline 1500 & 3672 & 19627 & 4824 & 12078 & 20095 & 103984 \\
\hline 2000 & 2304 & 11202 & 1584 & 11956 & 12417 & 105056 \\
\hline 2500 & 1584 & 11202 & 1368 & 8784 & 12591 & 101840 \\
\hline
\end{tabular}

